\title{
Fatigue model of domestic 316LN steel in simulated primary coolant environment of CAP1400
}

\author{
Weihua Zhong ${ }^{\mathrm{a}}$, Guian Qian ${ }^{\mathrm{b}, *}$, Zhenfeng Tong ${ }^{\mathrm{a}, *}$, Wenwang $\mathrm{Wu}^{\mathrm{c}}$, Shun-Peng Zhu ${ }^{\mathrm{d}}$, \\ Chenglong Wang ${ }^{\mathrm{a}}$ \\ ${ }^{a}$ China Institute of Atomic Energy, Beijing, China \\ ${ }^{\mathrm{b}}$ State Key Laboratory of Nonlinear Mechanics (LNM), Institute of Mechanics, Chinese Academy of Sciences, Beijing, China \\ ${ }^{\mathrm{c}}$ Institute of Advanced Structure Technology, Beijing Institute of Technology, Beijing 100081, China \\ ${ }^{\mathrm{d}}$ School of Mechanical and Electrical Engineering, University of Electronic Science and Technology of China, Chengdu 611731, China
}

\section{A R T I C L E I N F O}

\section{Keywords:}

Primary coolant pipe

Low cycle fatigue

Corrosion fatigue

Fatigue model

Environmental fatigue life

\begin{abstract}
A B S T R A C T
Fatigue tests of domestic 316LN were carried out in the simulated primary coolant environment of CAP1400 (the advanced 3rd generation nuclear power plants developed in China). Effects of temperature, strain rate and dissolved oxygen (DO) on fatigue life were analyzed. Based on the results, a fatigue model was developed. Fatigue life in primary coolant environment increases logarithmically as the temperature decreases from $321^{\circ} \mathrm{C}$ to $150{ }^{\circ} \mathrm{C}$. When the temperature decreases to $150{ }^{\circ} \mathrm{C}$, fatigue life in primary coolant environment is very close to that in air environment. Fatigue life increases as the strain rate increases from $0.004 \% / \mathrm{s}$ to $1 \% / \mathrm{s}$. After the strain increases to more than $0.4 \% / \mathrm{s}$, fatigue life in primary coolant environment is very close to that in air environment. Effect of DO on fatigue life in primary coolant environment is not obvious in the DO range of $0.005 \mathrm{ppm}$ to $8 \mathrm{ppm}$. Compared with NUREG6909 model, the present fatigue model is more accurate in lifetime prediction of domestic $316 \mathrm{LN}$.
\end{abstract}

\section{Introduction}

Developing Nuclear Power Plant (NPP) is an utmost strategy to achieve win-win goal of social development and low-carbon green environment in the world. Operation safety and economy is the most important and critical issue in the development of NPP. The primary coolant pipe is the key component that related to operation safety and economy, as it is the third barrier to prevent radioactive substance leak from reactor core and act as the artery of a nuclear island [1]. In the long term operation of structures, the integrity should be analyzed using different methods, e.g., deterministic and probabilistic methods [2-9]. The different ageing mechanism and failure modes should also be studied and advanced crack detection setups are developed [8-10]. As a result, new structures can be designed tailored to the applications $[11,12]$. During operation, the primary coolant pipe is subject to the changes of pressure, temperature, and fluid. The resultant secondary induced stresses will cause fatigue damage of the piping material. The damage can be aggravated by the primary coolant water environment, which is of high temperature, high pressure, etc. $[13,14]$ Therefore, in order to assess the integrity of the primary coolant pipe and determine its lifetime in service, a fatigue model in simulated primary coolant environment should be developed [15].

Based on the experimental test, a lot of fatigue models used in primary coolant, e.g., NUREG6909, JNES1005 [16,17], have been proposed. According to these fatigue models, some critical factors, such as temperature [18-20], strain rate [21-23] and dissolved oxygen (DO) [17], have important influence on fatigue life. As recommended in the RG1.207 guideline, the fatigue model in simulated primary coolant usually includes 2 parts, i.e., the fatigue model in air environment and the Environmental Fatigue Correction Factor (Fen) which is defined as the ratio of fatigue life in air at room temperature to that in water at the service temperature [24]. In this paper, both fatigue model in air and in environment will be studied.

316LN stainless steel is used as the primary coolant pipe material of CAP1400 NPP, which is one kind of the advanced 3rd generation NPPs developed in China $[25,26]$. Thus, material performance of 316LN and its fatigue lifetime prediction in service is significant to the operation safety of NPPs. Our previous work tested the fatigue property of 316LN in simulation primary coolant environment and the relationship between fatigue life and different strain amplitudes was obtained $[27,28]$. It is shown that fatigue crack propagation was accelerated in the primary coolant environment due to Environmental Assist Cracking (EAC)

\footnotetext{
* Corresponding authors.

E-mail addresses: qianguian@imech.ac.cn (G. Qian), tony_tzf@163.com (Z. Tong).
} 
Table 1

Chemical composition of 316LN steel.

\begin{tabular}{llll}
\hline Elements & $\mathrm{w}[\%]$ & Elements & $\mathrm{w}[\%]$ \\
\hline $\mathrm{C}$ & 0.012 & $\mathrm{Ni}$ & 13.12 \\
$\mathrm{Mn}$ & 1.23 & $\mathrm{Cr}$ & 17.01 \\
$\mathrm{Si}$ & $\mathrm{Mo}$ & 2.44 \\
$\mathrm{P}$ & 0.31 & $\mathrm{~N}$ & 0.14 \\
$\mathrm{~S}$ & 0.017 & $\mathrm{Co}$ & 0.01 \\
\hline
\end{tabular}

and the EAC mechanism is most likely to be Hydrogen Induced Crack (HIC) [28].

The aim of the present work is to study the fatigue model of the piping material on the basis of the experimental investigation. The effect of temperature, strain rate and dissolved oxygen on fatigue life are studied. A fatigue model in primary coolant environment is proposed and compared with the NUREG6909 model. The result is used to provide research basis to fatigue design and lifetime evaluation of primary coolant pipe of the domestic 3rd generation NPP.

\section{Experiment procedure}

The test material is $316 \mathrm{LN}$ stainless steel that cut from a primary coolant pipe. The nominal chemical composition is listed in Table 1. The metallographic structure of the material is typical austenite, as shown in Fig. 1. It is shown that most of the grains are white and in polygon shape. The grain boundary is straight, and a lot of twin grain existed within the grain. The average grain size is about $135 \mu \mathrm{m}$.

The cylindrical fatigue specimen is machined along the axial direction of the pipe, as shown in Fig. 2. The length and diameter of the gauge are $19 \mathrm{~mm}$ and $6.35 \mathrm{~mm}$, respectively. Fatigue tests were carried out in Bairoe corrosion fatigue test machine at different temperature $\left(100-325^{\circ} \mathrm{C}\right)$, strain rate $(0.004-1 \%)$ and DO $(0.1-8 \mathrm{ppm})$ in order to study the effect on fatigue property. The test environment is simulation CAP1400 first loop water environment. The detailed environment parameters are listed in Table 2 . The triangular waveform loading with the strain ratio of -1 is applied.

Fatigue life $\left(\mathrm{N}_{\mathrm{f}}\right)$ is defined as the number of cycles for tensile stress to drop $25 \%$ from its peak value [29].

\section{Results}

Fatigue life tested in primary coolant environment at different strain rate is shown in Fig. 3. Fatigue life increases from around 2000 to 6000 cycles as the strain rate increases from $0.004 \% / \mathrm{s}$ to $1 \% / \mathrm{s}$; fatigue life decreases logarithmically as the strain rate decreases. In order to study the difference between fatigue behavior in air environment and primary

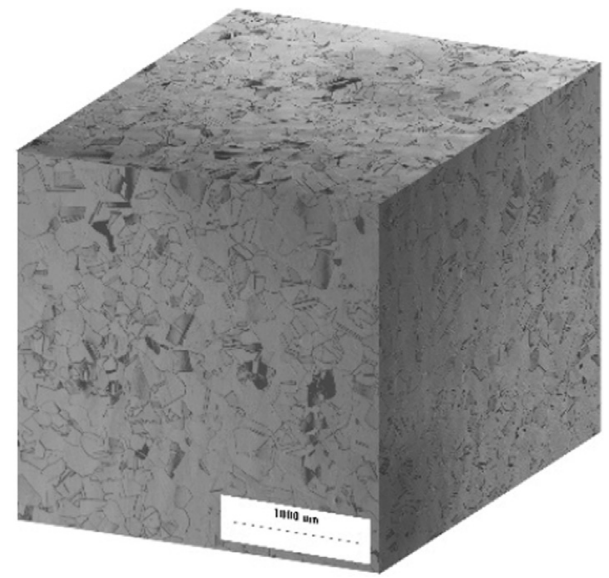

Fig. 1. Metallograph of domestic 316LN stainless steel.

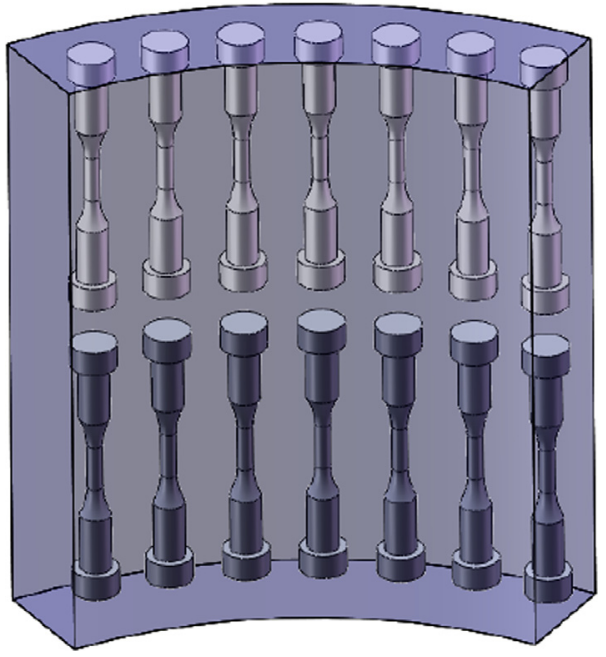

Fig. 2. Sampling site of billet.

Table 2

Primary coolant environment parameters of CAP1400.

\begin{tabular}{ll}
\hline Parameters & Primary coolant environment \\
\hline Temperature & $321\left[{ }^{\circ} \mathrm{C}\right]$ \\
Pressure & $15.5[\mathrm{MPa}]$ \\
Dissolved oxygen & $5-100[\mathrm{ppb}]$ \\
$\mathrm{pH}$ control agent & $2.2[\mathrm{ppm}] \mathrm{LiOH}+1200[\mathrm{ppm}] \mathrm{H}_{3} \mathrm{BO}_{3}$ \\
Conductivity & $20-35[\mu \mathrm{S} / \mathrm{cm}]$ \\
$\mathrm{pH}$ & $6-7$ \\
\hline
\end{tabular}

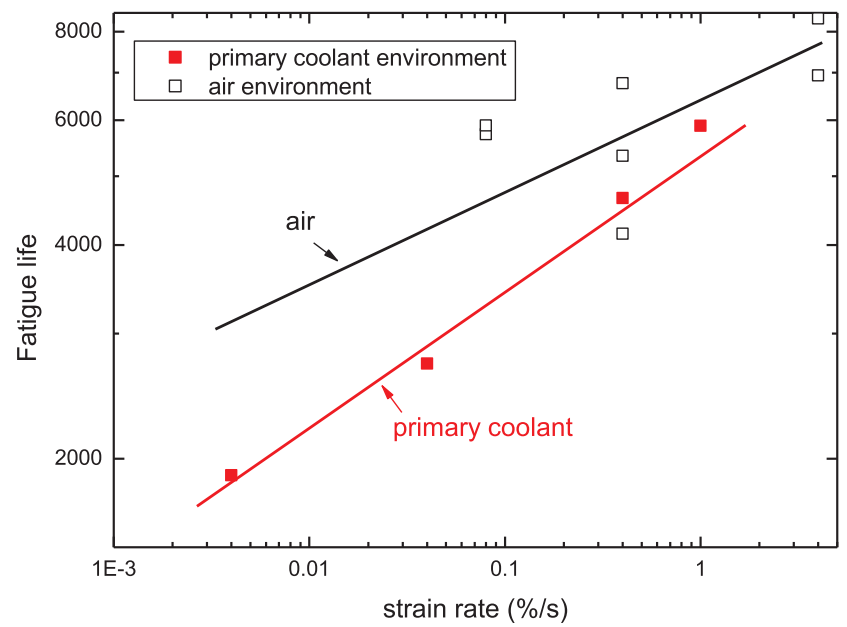

Fig. 3. Effect of strain rate to fatigue life in primary coolant environment.

coolant environment, fatigue life in air environment [30] is presented in Fig. 3. It is seen that fatigue life of air environment is higher than that in primary coolant environment. The variation of fatigue life with strain in air environment is similar to that in primary coolant environment, except that the slope of trend line is much steeper in primary coolant, indicating the effect of strain rate is more pronounced in primary coolant. Furthermore, as the strain rate increases from $0.004 \% / \mathrm{s}$ to $1 \%$, the fatigue data in different environment is approaching to each other. After the strain increases to more than $0.4 \% / \mathrm{s}$, fatigue life in primary coolant environment approaches to that in air environment. This aforementioned behavior indicated that when the strain rate is high enough, fatigue life won't be reduced in primary coolant environment. The similar behavior is also found for other stainless steel, e.g., 304, $316 \mathrm{NG}[16,17]$. Actually for a long lifetime operation of nuclear power 


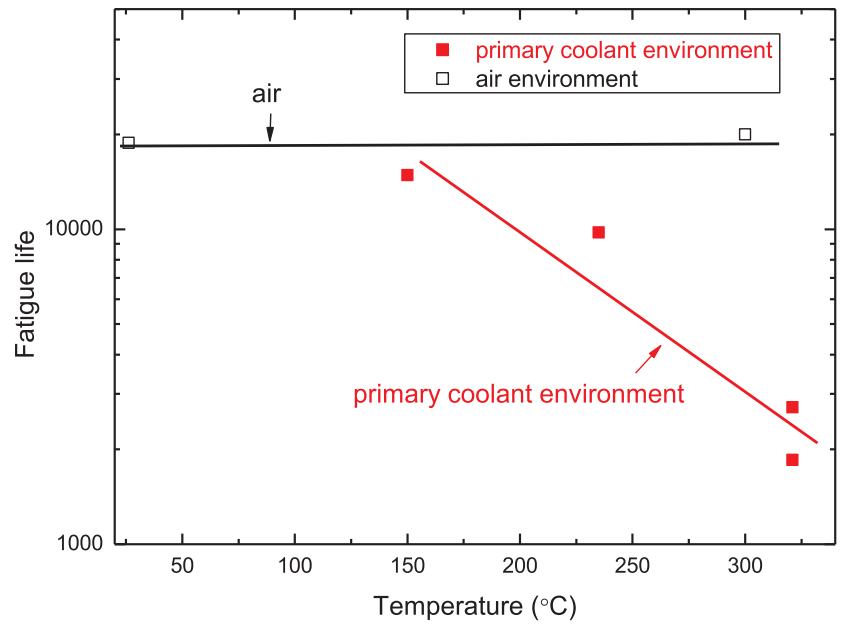

Fig. 4. Effect of temperature to fatigue life in primary coolant environment.

plant, the structures and components may be subjected to longer loading of cycles, i.e., longer than $10^{7}$ cycles. In this sense, very high cycle fatigue is an important topic. However, the focus of this paper is on low and high cycle fatigue. The scenario considered are some big loadings and the loading frequency is quite low. In the next phase, the study will be moved to very high cycle fatigue with similar methods and considerations.

Effect of temperature on fatigue life in primary coolant environment is shown in Fig. 4. As the temperature increases from $150^{\circ} \mathrm{C}$ to $321^{\circ} \mathrm{C}$, fatigue life of 316LN S.S is which tested at the strain amplitude of $0.4 \%$ decreases from around 15,000 to 2000 cycles. Fatigue life decreases linear as the temperature decreases from $321^{\circ} \mathrm{C}$ to $150^{\circ} \mathrm{C}$. Fatigue life in air environment is also presented in this figure. It is seen that temperature doesn't display pronounced effect on fatigue life. As the temperature decreases from $321^{\circ} \mathrm{C}$ to $150{ }^{\circ} \mathrm{C}$, fatigue life is approaching to each other. After the temperature decreases to $150^{\circ} \mathrm{C}$, fatigue life of primary coolant environment is very close to that of air environment. The above behavior is similar to other stainless steel.

Effect of DO on fatigue life in primary coolant environment is shown in Fig. 5. The listed data includes fatigue life of $316 \mathrm{LN}$ tested in different DO and strain amplitude. The variation of fatigue life with DO and strain amplitude is also shown. It is seen that as DO increases from $0.005 \mathrm{ppm}$ to $8 \mathrm{ppm}$, fatigue life of the specimens tested at the same strain amplitude does not change significantly. This indicates that the effect of DO on fatigue life of 316LN S.S is not obvious, which is in agreement with the behavior of other stainless steels $[16,17]$. This is

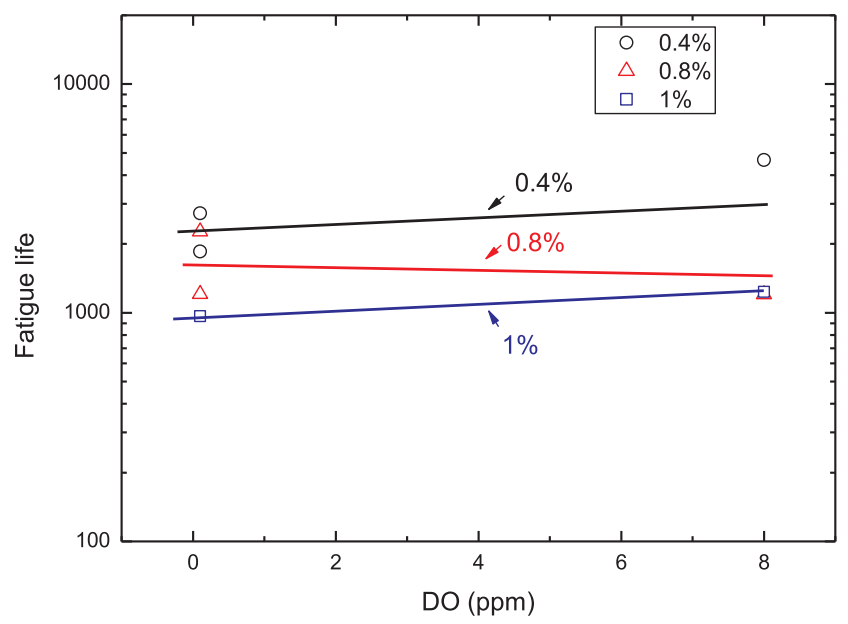

Fig. 5. Effect of DO to fatigue life in primary coolant environment. because that for 316LN, the environmental assisted cracking mechanism in primary coolant environment is most likely to be hydrogen-induced cracking. This mechanism is not determined by the dissolved oxygen $[16,17]$.

\section{Discussion}

As mentioned above, effects of primary coolant environments on fatigue life is expressed in terms of environmental fatigue correction factor, i.e., Fen, which is defined as the ratio of fatigue life in air at room temperature to that in primary coolant environment. Thus, in order to develop fatigue life model in primary coolant environment, both fatigue life models in air environment and Fen should be studied firstly.

\subsection{Fatigue life model in air environment}

The commonly used fatigue life model is Mason-Coffin model according to the test standards. However, for the sake of engineering application, the Langer model is implemented in the NUREG6909 and JNES1005 as the fatigue life model. Therefore, the Langer model is also used in this paper to fit the fatigue life model of domestic 316LN steel in air environment. It is fitted according to the data in [27], as

$\ln \left(\mathrm{N}_{\mathrm{f}}\right)=6.91-2.26 \times \ln \left(\varepsilon_{\mathrm{a}}-0.086\right.$

where, $\mathrm{N}_{\mathrm{f}}$ is fatigue life, $\varepsilon_{a}$ is strain amplitude.

Fig. 6 shows the fatigue data and life model of domestic 316LN tested in air environment. It is seen that the fatigue behavior of domestic 316LN is similar to that of reference, i.e., NUREG6909 and JNES1005.

Fig. 7 compares the model prediction data of domestic 316LN in air environment with the experimental data. A general agreement is found and the ratio of prediction data to the test data is within 3. The NUREG6909 model also demonstrates good agreement with the test data. Nevertheless, the prediction is not as accurate as the model of this paper.

\subsection{Fen and fatigue model in primary coolant environment}

Fatigue model in primary coolant environment is established based on Fen and fatigue property in air environment. Fen is usually proposed based on the effect of different important factors.

Substantial researches confirmed that $[16,17]$ a lot of factors, i.e., strain rate, temperature, strain rate, DO, load waveform and rate of flow, etc., have important influence on Fen. Among these factors,

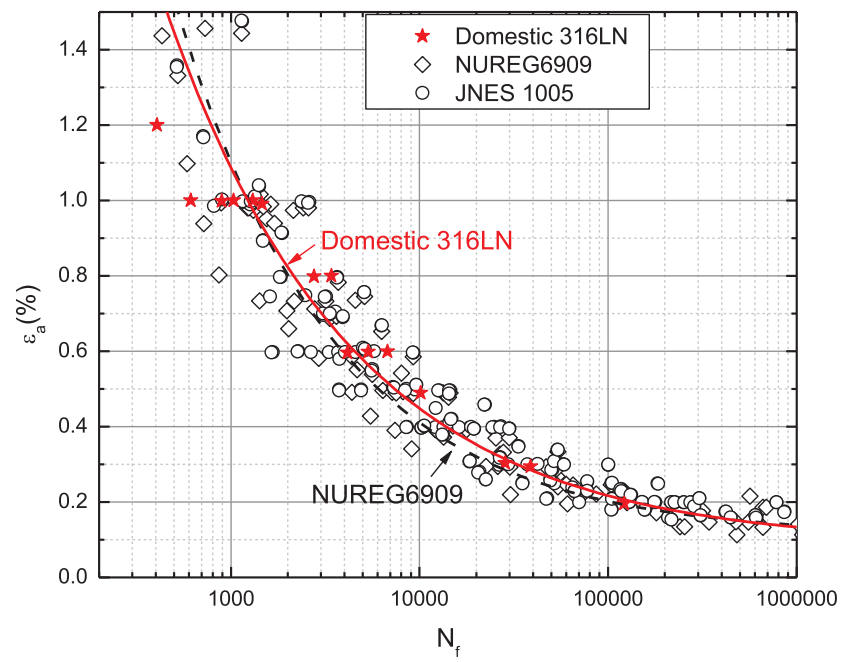

Fig. 6. Fatigue data and life model of domestic 316LN in air environment. 


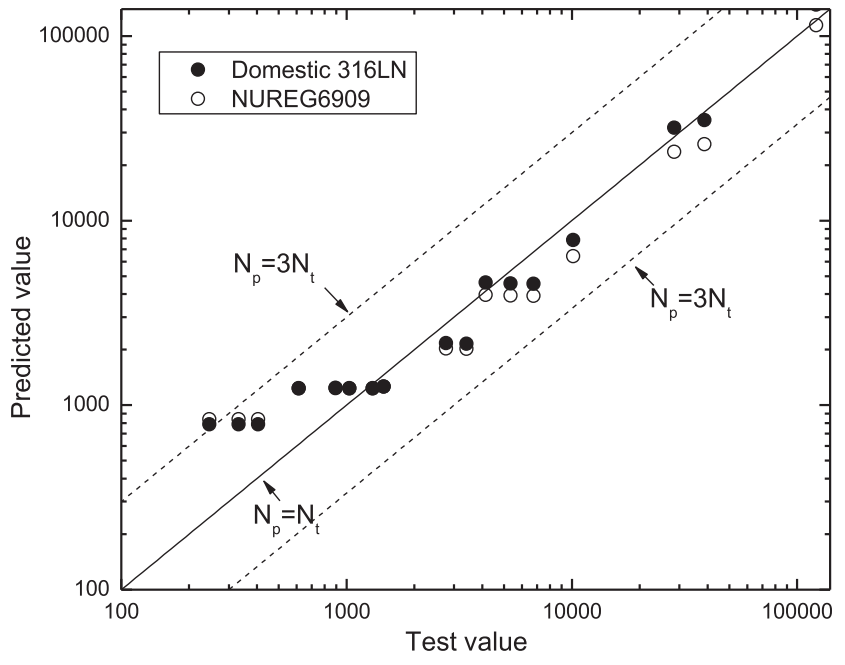

Fig. 7. Comparison of test data and model prediction data of domestic 316LN steel in air environment.

temperature, strain rate and DO are the critical ones that should be considered carefully. As the experiment results proved that DO may not affect the fatigue life of $316 \mathrm{LN}$, only temperature and strain rate are considered in this paper. The focus of the paper is on the effect of strain rate, temperature and different environmental medias on fatigue life. The fatigue range is more on low and high cycle fatigue, where the stress range is relatively high. Crack initiation mainly started from the specimen surface due to surface cracks and persistent slip band. In environmental media, fatigue crack initiated under the synergistic effect of stress and hydrogen.

\subsubsection{Effect of temperature}

Effect of temperature on Fen of primary coolant pipe is shown in Fig. 8. In addition to the experiment data, the reference data with similar material parameter is also collected and is presented in this figure [16-18]. It can be seen that for the domestic 316LN, the logarithm of Fen decreased linear as the temperature decreased from $321^{\circ} \mathrm{C}$ to $150^{\circ} \mathrm{C}$. Fen is constant as the temperature decreases to below $150^{\circ} \mathrm{C}$. The variation trend of domestic $316 \mathrm{LN}$ is similar to that of reference material. According to the experimental data and reference data, the relationship between temperature and Fen at the temperature range of $325^{\circ} \mathrm{C}$ to $150{ }^{\circ} \mathrm{C}$ is fitted as

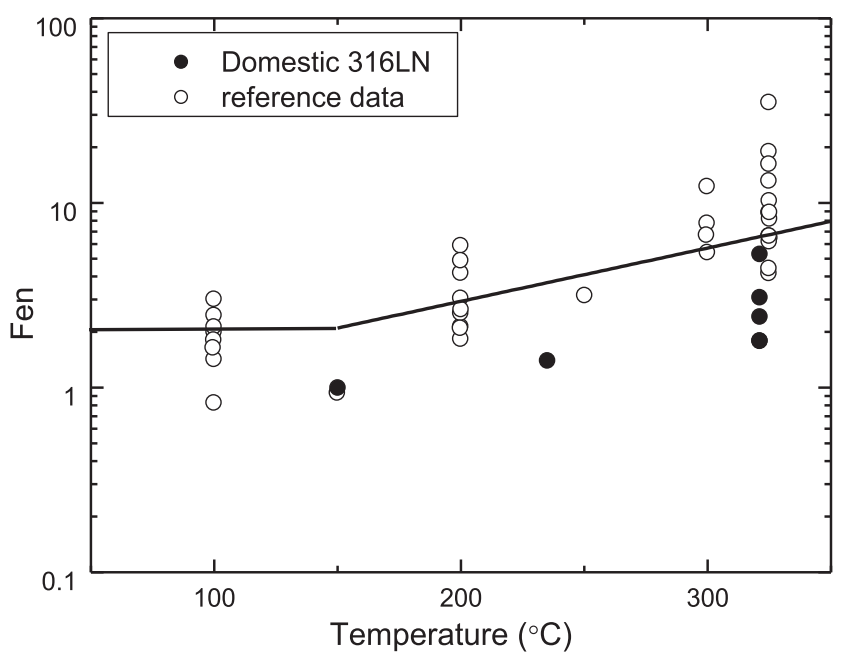

Fig. 8. Effect of temperature to Fen of primary coolant pipe in primary coolant environment.

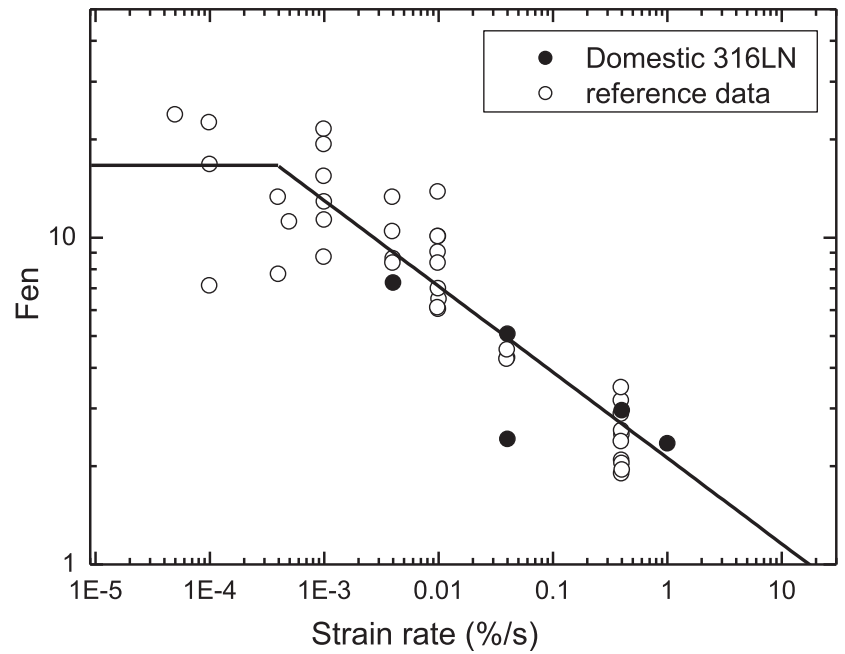

Fig. 9. Effect of strain rate to Fen of primary coolant pipe in primary coolant environment.

$\ln \left(\mathrm{F}_{\mathrm{en}}\right)=0.0066 \times \mathrm{T}-0.254$

where Fen is the environmental fatigue correct factor, $\mathrm{T}$ is the temperature in ${ }^{\circ} \mathrm{C}$.

\subsubsection{Effect of strain rate}

Effect of strain rate on Fen of primary coolant pipe is shown in Fig. 9. The experimental data of domestic 316LN, together with the reference data which the test material and test parameter are similar to $316 \mathrm{LN}$, are listed in the figure $[16,31]$. It is seen that in the strain rate range from $0.004 \% / \mathrm{s}$ to $0.4 \% / \mathrm{s}$, the experimental data is in good agreement with the reference data. Fen decreases as strain rate decreases in the range from $0.0004 \% / \mathrm{s}$ to $0.4 \% / \mathrm{s}$, and it keeps constant as the strain rate decreases to below $0.0004 \% / \mathrm{s}$.

As the test data and reference data illustrate similar property, effect of strain rate on Fen can be studied according to the data of both materials. The relationship between strain rate and Fen is fitted as

$\ln \left(\mathrm{F}_{\mathrm{en}}\right)=0.750-0.263 \times \ln (\dot{\varepsilon})$

where $\dot{\varepsilon}$ is the strain rate in $\% / \mathrm{s}$, the strain rate is from $0.0004 \% / \mathrm{s}$ to $0.4 \% / \mathrm{s}$.

4.2.3. Fatigue design curve considering effect of primary coolant environment

According to the discussion of research results [16], the Fen of domestic 316LN can be express as:

$\ln \left(\mathrm{F}_{\mathrm{en}}\right)=\mathrm{A}+\mathrm{B} \times \mathrm{X}_{\mathrm{T}} \times \mathrm{X}_{\varepsilon}$

where, $A$ and $B$ are coefficients that can be calculated out according to the test data, $\mathrm{X}_{\mathrm{T}}$ and $\mathrm{X}_{\varepsilon}$ are transformed temperature and strain rate, respectively, defined as

$\left\{\begin{array}{lc}X_{T}=0 & \left(T \leqslant 150^{\circ} \mathrm{C}\right) \\ X_{T}=(T-150) & \left(T>150^{\circ} \mathrm{C}\right)\end{array}\right.$
$\left\{\begin{array}{cc}X_{\varepsilon}=0 & \left(\varepsilon>1 \% s^{-1}\right) \\ X_{\varepsilon}=\ln (\varepsilon) & \left(0.001 \% s^{-1} \leqslant \varepsilon \leqslant 1 \% s^{-1}\right) \\ X_{\varepsilon}=\ln (0.001) & \left(\varepsilon<0.001 \% s^{-1}\right)\end{array}\right.$

According to the test data, Fen of domestic $316 \mathrm{LN}$ is fitted as

$\ln \left(\mathrm{F}_{\mathrm{en}}\right)=0.498-0.203 \times \mathrm{X}_{\mathrm{T}} \times \mathrm{X}_{\varepsilon}$

Further, by combining the fatigue life model in air environment and Fen, fatigue life of domestic $316 \mathrm{LN}$ in primary coolant environment is obtained as 


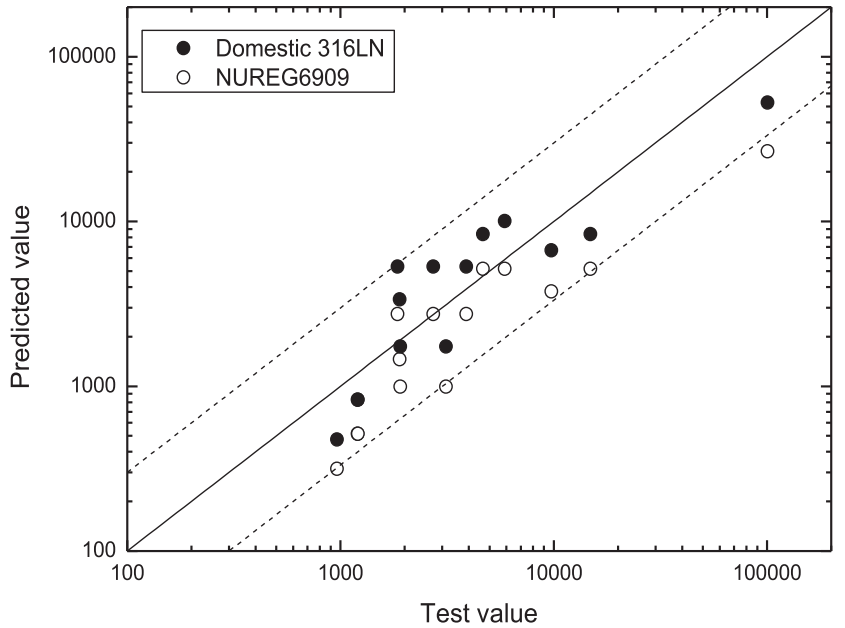

Fig. 10. Comparison of test data and model prediction data of domestic 316LN in primary coolant environment.

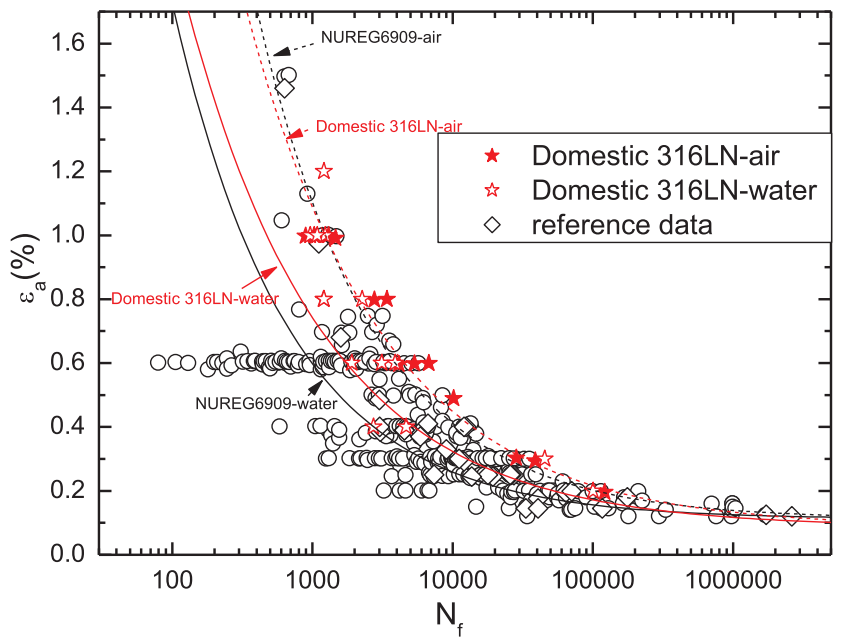

Fig. 11. Relationship of fatigue life and strain amplitude of domestic 316LN in different environment.

$\ln \left(\mathrm{N}_{\mathrm{f}}\right)=6.412-2.26 \times \ln \left(\varepsilon_{\mathrm{a}}-0.086\right)+0.203 \times \mathrm{X}_{\mathrm{T}} \times \mathrm{X}_{\varepsilon}$

Fig. 10 shows the comparison of test data and model prediction data of domestic 316LN in primary coolant environment. It is seen that the model prediction shows good agreement with the test data. The ratio of prediction data to the test data is within 3. The prediction data by NUREG-6909 model are slightly lower than the model prediction in this paper, indicating that the predicted values of NUREG6909 model is not as accurate as the model developed in this paper.

The relationship between fatigue life and strain amplitude of primary coolant pipe in different environment is shown in Fig. 11. It is clear that all the test data fall within the range of reference data. The fatigue life of domestic 316LN in primary coolant environment is lower than that in air environment, which indicates pronounced EAC effect in primary coolant environment. Compared to NUREG6909 model, fatigue life prediction in this paper is slightly higher that of NUREG6909 model. The model developed in this paper shows better agreement with the fatigue data of domestic $316 \mathrm{LN}$, indicating that the presented model is more applicable for fatigue life prediction.

In order to characterize the dispersion, we need to perform a P-S-N analysis based on probabilistic analysis. The probabilistic fatigue study is an important aspect, especially for the engineering application of the experimental data. There are some fundamental models started from micro crack distributions. The existing models for the uncertainty analysis are comprehensively reviewed by Qian and Lei [2]. For a solid of volume (V) subjected to a cyclic load (S) for a certain number of loading cycles $(\mathrm{N})$, its fatigue failure is a random event. This indicates that the cumulative probability $(\mathrm{P})$ for the occurrence of fatigue failure depends on the cyclic load (S), number of loading cycles (N), and specimen size $(\mathrm{V})$. This allows one to describe the cumulative probability (P) of fatigue failure of a solid as a function of cyclic load (S), number of loading cycles $(\mathrm{N})$ and the volume $(\mathrm{V})$ of solid as follows: $P=F(S, N, V)$.

On one hand, the experimental data tested in different environmental medias, different strain ratio and temperatures help to understand the fundamental effect on fatigue life. On the other hand, the experimental data can be used to perform lifetime prediction and extension for a nuclear power plant. Using the S-N curve, the lifetime can be predicted, which is a part of fatigue design curve. Furthermore, a probabilistic modelling of the S-N curve gives a confidence level of the lifetime prediction.

\section{Conclusions}

In this paper, fatigue property of domestic $316 \mathrm{LN}$ in primary coolant environment of NPP was investigated. Effect of temperature, strain rate and dissolved oxygen on fatigue life were studied. A fatigue life model was developed and compared with the NUREG6909 model. The following conclusions are drawn:

1) Fatigue life in primary coolant environment increases as the temperature decreases from $321^{\circ} \mathrm{C}$ to $150^{\circ} \mathrm{C}$. After the temperature decreases to $150^{\circ} \mathrm{C}$, fatigue life in primary coolant environment is very close to that in air environment.

2) The logarithm of fatigue life increases with the decrease of strain rate, in the strain rate range of $0.0004 \% / \mathrm{s}-0.4 \% / \mathrm{s}$. Effect of strain rate on fatigue life in primary coolant environment is similar to that in air environment. After the strain increases to more than $0.4 \% / \mathrm{s}$, the fatigue life in primary coolant environment is very close to that in air environment.

3) Effect of DO on fatigue life of 316LN S.S in primary coolant is not obvious in the range of DO from $0.005 \mathrm{ppm}$ to $8 \mathrm{ppm}$.

4) The model presented in this paper is more accurate than the NUREG6909 model in fatigue life prediction of domestic 316LN.

\section{Acknowledgement}

Financial support by National Natural Science Foundation of China (No. 11872364) and by CAS Pioneer Hundred Talents Program is acknowledged.

\section{References}

[1] Yang W. Reactor material science. Beijing: Atomic Energy Press; 2000.

[2] Qian G, Lei W. A statistical model of fatigue failure incorporating effects of specimen size and load amplitude on fatigue life. Phil Mag 2019. https://doi.org/10. 1080/14786435.2019.1609707.

[3] Liao D, Zhu S, Qian G. Multiaxial fatigue analysis of notched components using combined critical plane and critical distance approach. Inter J Mech Sci 2019;160:38-50.

[4] Qian G, Lei W, Tong Z, Yu Z. A statistical model of cleavage fracture toughness of ferritic steel DIN 22NiMoCr37 at different temperatures. Materials 2019;12:982.

[5] Zhu SP, Foletti S, Beretta S. Evaluation of size effect on strain-controlled fatigue behavior of a quench and tempered rotor steel: experimental and numerical study. Mat. Sci. Eng. A 2018;735:423-35.

[6] Qian G, Lei W, Yu Z, Berto F. Statistical size scaling of breakage strength of irregularly-shaped particles. Theo App Fract Mech 2019;102:51-8.

[7] Xu S, Zhu S, Hao Y, Qian G. A new critical plane-energy model for multiaxial fatigue life prediction of turbine disc alloys. Eng Fail Anal 2018;93:55-63.

[8] Qian G, Lei W-S, Peng L, Yu Z, Niffengger M. Statistical assessment of notch toughness against cleavage fracture of ferritic steels. Fatigue Fract Eng Mater Struct 2018;41:1120-31.

[9] Qian G, Lei W-S, Niffenegger M, Gonzalez VF. On the temperature independence of statistical model parameters for cleavage fracture in ferritic steels. Philo Mag 2018;98:959-1004. 
[10] Wang Z, Wu W, Qian G, Oliveira Correia J, Sun L. In-situ SEM investigation on fatigue behaviors of additive manufactured Al-Si10-Mg alloy at elevated temperature. Eng Fract Mech 2019;214:149-63.

[11] Wu W, Hu W, Qian G, Liao H, Xu X, Berto F. Mechanical design and multifunctional applications of chiral mechanical metamaterials: a review. Mater Des 2019;18(107950):1-13.

[12] Wu W, Song X, Liang J, Xia R, Qian G, Fang D. Mechanical properties of antitetrachiralauxetic stents. Comp Struct 2018;185:381-92.

[13] Kamaya M. Environmental effect on fatigue strength of stainless steel in PWR primary water-role of crack growth acceleration in fatigue life reduction. Int J Fatigue 2013;55:102-11.

[14] Du D, Wang J, Chen K, Zhang L, Andresen PL. Environmentally assisted cracking of forged 316LN stainless steel and its weld in high temperature water. Corro Sci 2019;147:69-80.

[15] Asme SI. Boiler and pressure vessel code, rules for construction of nuclear power plant components. New York, NY: American Society of Mechanical Engineers; 1992.

[16] Chopra WJSOK. Effect of LWR coolant environments on the fatigue life of reactor materials. NUREG/CR-6909. Argonne National Laboratory; 2007.

[17] Nuclear energy system safety division, Japan Nuclear Energy Safety Organization. Environmental fatigue evaluation method for nuclear power plants. JNES-SS-1005; 2011.

[18] Chopra OK, Alexandreanu B, Shack WJ. Effect of material heat treatment on fatigue crack initiation in austenitic stainless steels in LWR environments, NUREGCR-6878. NUREG/CR-6878, Argonne National Laboratory, Effect of Material Heat Treatment on Fatigue Crack Initiation in Austenitic Stainless Steels in LWR Environments 2005. NUREGCR-6878.

[19] Higuchi M, Tsutsumi K, Hirano A, Sakaguchi K. A Proposal of fatigue life correction factor fen for austenitic stainless steels in LWR water environments. ASME J Press Vessel Tech 2003;125:403.

[20] Zhang Z, Tan J, Wu X, Han E-H, Ke W, Rao J. Effects of temperature on corrosion fatigue behavior of 316LN stainless steel in high-temperature pressurized water. Corro Sci 2019;146:80-9.

[21] Higuchi M, Sakaguchi K, Nomura Y, Hirano A. Final Proposal of Environmental Fatigue Life. 2007 ASME Pressure Vessels and Piping Division Conference,. San Antonio, Texas: ASME; 2007.

[22] Zhang Z, Tan J, Wu X, Han E-H, Ke W. Synergistic effect of mechanical and environmental damages of 316LN stainless steel under different fatigue strain amplitudes in high-temperature pressurized water. Mater Sci Eng, A 2019;743:243-50.

[23] Hong J-D, Jang C, Kim TS. Effects of mixed strain rates on low cycle fatigue behaviors of austenitic stainless steels in a simulated PWR environment. Int J Fatigue 2016;82:292-9.

[24] NRC. RG1.207. Guidelines for evaluating fatigue analyses incorporating the life reduction of the light-water reactor environment for new reactor. U.S. Nuclear Regulatory Commission; 2007.

[25] Zheng M, Yang J, Jun S, Tian L, Wang X, Qiu Z. The general design and technology innovations of CAP1400. Engineering 2016;2:97-102.

[26] Ge L. Passive safety advanced NPP AP1000. Beijing: Atomic Energy Press; 2008.

[27] Zhong W, Tong Z, Wang C, Wang Z, Li J, Yang W. Fatigue behavior of domestic 316LN under Simulated AP1000 first loop water environment. Atom Energy Sci Tech 2017;51:1846-52.

[28] Zhong WH, Tong ZF, Wang Z, Li JX, Yang W. Fatigue mechanism of domestic 316LN stainless steel in simulated AP1000 first-loop water environment. Mater Sci Forum 2018;913:247-53.

[29] Standard CN. Metallic materials - fatigue testing - axial strain-controlled method. GBT 2010;26077

[30] Zhong W, Yu B, Tong Z, Ning G. Research on low cycle fatigue behavior of domestic 316LN stainless steel at room temperature. Hot Work Technol 2017:46:66-73.

[31] Tan J, Wu X, Han E-H, Ke W, Wang X, Sun H. Strain-rate dependent fatigue behavior of 316LN stainless steel in high-temperature water. J Nucl Mater 2017;489:33-41. 